\title{
A protocol describing the genetic correction of somatic human cells and subsequent generation of iPS cells
}

\author{
Ángel Raya ${ }^{1,2,3,8}$, Ignasi Rodríguez-Pizà ${ }^{1}$, Susana Navarro ${ }^{4,5}$, Yvonne Richaud-Patin $^{1,3,8}$, Guillermo Guenechea ${ }^{4,5}$, \\ Adriana Sánchez-Danés ${ }^{1,9}$, Antonella Consiglio ${ }^{1,6,9}$, Juan Bueren ${ }^{4,5}$ \& Juan Carlos Izpisúa Belmonte ${ }^{1,7}$
}

\begin{abstract}
${ }^{1}$ Center for Regenerative Medicine in Barcelona, Barcelona, Spain. ${ }^{2}$ Institució Catalana de Recerca i Estudis Avançats (ICREA), Barcelona, Spain. ${ }^{3}$ Networking Center of Biomedical Research in Bioengineering, Biomaterials and Nanomedicine (CIBER-BBN), Barcelona, Spain. ${ }^{4}$ Hematopoiesis and Gene Therapy Division, Centro de Investigaciones Energéticas, Medioambientales y Tecnológicas (CIEMAT), Madrid, Spain. ${ }^{5}$ Networking Center of Biomedical Research in Rare Diseases (CIBERER), Madrid, Spain. ${ }^{6}$ Department of Biomedical Science and Biotechnology, University of Brescia, Brescia, Italy. ${ }^{7}$ Gene Expression Laboratory, Salk Institute for Biological Studies, La Jolla, California, USA. ${ }^{8}$ Present address: Control of Stem Cell Potency Group, Institute for Bioengineering of Catalonia (IBEC), Baldiri Reixac 15, Barcelona, Spain. ${ }^{~}$ Present address: Institute of Biomedicine of the University of Barcelona (IBUB), Baldiri Reixac 15, Barcelona, Spain. Correspondence should be addressed to J.C.I.B. (belmonte@salk.edu; izpisua@cmrb.eu).
\end{abstract}

Published online 11 March 2010; doi:10.1038/nprot.2010.9

\begin{abstract}
The generation of patient-specific induced pluripotent stem cells (iPSCs) offers unprecedented opportunities for modeling and treating human disease. In combination with gene therapy, the iPSC technology can be used to generate disease-free progenitor cells of potential interest for autologous cell therapy. We explain a protocol for the reproducible generation of genetically corrected iPSCs starting from the skin biopsies of Fanconi anemia patients using retroviral transduction with OCT4, SOX2 and KLF4. Before reprogramming, the fibroblasts and/or keratinocytes of the patients are genetically corrected with lentiviruses expressing FANCA. The same approach may be used for other diseases susceptible to gene therapy correction. Genetically corrected, characterized lines of patient-specific iPSCs can be obtained in 4-5 months.
\end{abstract}

\section{INTRODUCTION}

The generation of induced pluripotent stem cells (iPSCs) by ectopic expression of a defined set of factors ${ }^{1-5}$ has enabled the derivation of disease-specific pluripotent cells and provided valuable experimental platforms to model human disease ${ }^{6-8}$. Moreover, for genetic diseases amenable to gene therapy correction, reprogramming of genetically corrected somatic cells can be used to generate diseasefree progenitor cells with potential value for autologous cell therapy applications ${ }^{9}$.

Fanconi anemia (FA) is a rare genetic disease causing chromosomal instability that frequently results in early-onset bone marrow failure. When this occurs, the treatment of choice is the transplantation of hematopoietic grafts from human leukocyte antigen-identical siblings, which is obviously limited by availability. A variety of gene therapy strategies have been implemented for FA and have shown to provide functional correction in vitro and in vivo, but the success of clinical trials has been limited probably because of the paucity and poor quality of hematopoietic stem cells in the bone marrow of FA patients. For these reasons, FA provides an interesting paradigm in which genetically corrected, non-hematopoietic somatic cells could be reprogrammed to generate disease-corrected, patient-specific iPSCs which, in turn, could be used to produce large numbers of autologous hematopoietic progenitors to restore the hematopoietic function in these patients.

One of the main factors limiting the applicability of iPSC-based strategies is the extremely low efficiency of the reprogramming process, particularly when starting from clinically relevant human samples, such as adult dermal fibroblasts. To date, the most efficient way to induce reprogramming of human adult fibroblasts that remains is the original Yamanaka's method of retroviral transduction with OCT4, SOX2, KLF4 and c-MYC (OSKM) (see ref. 1), which can be further improved by co-transduction with hTERT (human telomerase reverse transcriptase) and SV40 large $\mathrm{T}^{4}$ or by blocking p53 activity ${ }^{10-12}$. However, introducing additional oncogenes or reducing the activity of tumor suppressors may increase the cancer risk of iPSCs. Epidermal keratinocytes are much more efficiently reprogrammed than fibroblasts by the four Yamanaka factors, but this efficiency drops dramatically when c-MYC is omitted $^{13}$. Therefore, although successful reprogramming of patients' somatic cells without c-MYC has been reported in the context of $\mathrm{FA}^{9}$, the low efficiency of the overall process may limit the applicability of this strategy.

Detailed protocols on the generation of iPSCs from mouse ${ }^{14}$ and human ${ }^{15}$ fibroblasts have been published. Here we describe a protocol for the generation of genetically corrected iPSCs by retroviral transduction with OCT4, SOX2 and KLF4 (OSK). The protocol is based on our recent studies on the successful generation of diseasefree FA-specific iPSCs 9 . The improved efficiency of the protocol described here mainly relies on the use of low-passage, freshly isolated primary cultures of patients' somatic cells, dermal fibroblasts or epidermal keratinocytes. Moreover, further refinements in the timing of isolation, genetic correction and reprogramming of the somatic cells result in consistent generation of patientspecific iPSCs in the absence of c-MYC transduction in $~ 90 \%$ of the attempts. We include a 'positive control' for reprogramming using the four Yamanaka factors, which can be particularly helpful if the starting material consists of already established primary cultures, instead of biopsy specimens. Finally, we have omitted the $2 \mathrm{i}$ selection step based on the combined inhibition of MEK1 and GSK3 using inhibitors PD0325901 and CT99021 (see ref. 16), which we no longer find necessary but can be included in the case of fibroblasts unusually refractory to reprogramming.

The protocol described here should be applicable to any genetic disease for which gene therapy can achieve functional correction 
of the disease phenotype at the cellular level. In the case of FA, genetic correction of patients' somatic cells must be done before reprogramming, as a functional FA pathway seems to be necessary for iPSC generation ${ }^{9}$. For diseases in which this is not the case, genetic correction can be performed before or after reprogramming, the former having the advantage that iPSC lines would represent clonal integration event(s) of the correcting transgene. Genetically corrected iPSC lines generated using this protocol should solely be used for research purposes, as they contain random integrations of reprogramming and correcting transgenes and, thus, will not be suitable for clinical application. In addition, this protocol can be used as a starting point to ascertain whether integration-free reprogramming protocols ${ }^{17-19}$ can be efficiently combined with novel gene correction approaches using engineered zinc finger nuclease ${ }^{20}$ for the generation of safer, genetically corrected iPSCs.

\section{MATERIALS}

\section{REAGENTS}

- Skin punch biopsy of the patient $(\sim 4 \mathrm{~mm})$ ! CAUTION Patients' recruitment into the study and subsequent sample procurement must be done after obtaining written informed consent under the protocols previously approved by the institutional review board. In addition, the generation of human iPSC lines in certain countries requires prior approval by specific Research Oversight Committees (e.g., in Spain, Comisión de Seguimiento y Control de la Donación de Células y Tejidos Humanos del Instituto de Salud Carlos III).

- Lentiviral vectors (LVs) with regulatory elements capable of driving therapeutic expression levels of the correcting transgene in iPSCs and differentiated cells (see REAGENT SETUP) $\boldsymbol{\Delta}$ CRITICAL The achievement of threshold expression levels of the correcting transgene will strongly depend on the specific condition to be treated. In some instances, weak expression levels will be enough to exert a therapeutic effect on the affected cell, whereas in others, only high expression levels of the transgene will be therapeutic. In addition, the potency of the promoter will be strongly dependent on the cell lineage toward which the iPSCs are differentiated. In our example, the SFFV (spleen focus-forming virus) promoter used in the therapeutic LV is particularly potent in hematopoietic stem cells ${ }^{21}$. Other promoters might be chosen depending on the specific cell population to be treated by the therapeutic vector.

- Retroviral vectors expressing the reprogramming transgenes (see REAGENT SETUP)

- 293T cells (ATCC, cat. no. CRL-11268)

- HT-1080 cells (ATCC, cat. no. CCL-121)

- Phoenix Amphotropic cells (ATCC, cat. no. SD 3443)

- Mitotically inactivated human foreskin fibroblasts (HFF) (ATCC, cat. no. CRL-2429) (see Box 1)

- $0.1 \%$ (wt/vol) Gelatin solution (Millipore, cat. no. ES-006-B)

- Matrigel (Mg, BD Biosciences, cat. no. 356234) (see Box 2)

- Dulbecco's PBS, without $\mathrm{Ca}^{2+}$ or $\mathrm{Mg}^{2+}$ (PAA laboratories $\mathrm{GmbH}$, cat. no. H15-002)

- DMEM (Invitrogen, cat. no. 21969-035)

- IMDM (Iscove's modified Dulbecco's medium, Invitrogen, cat. no. 21980-065)

- KO-DMEM (Knockout DMEM, Invitrogen, cat. no. 10829-018)

- Fetal calf serum (FCS, Perbio, Hyclone, cat. no. CH30160.03)

- Heat-inactivated fetal bovine serum (FBS, Invitrogen, cat. no. 10270-106)

- Knockout Serum Replacement (KO-SR, Invitrogen, cat. no. 10828-028)

- Trypan Blue stain (Invitrogen, cat. no. 15250-061)

- 20\% (wt/vol) Human serum albumin (HSA, Instituto Grifols SA, cat. no. 670612)

- GlutaMAX (Invitrogen, cat. no. 35050-038)

- Minimum essential medium Eagle’s nonessential amino acids, 100X

(Lonza, cat. no. BE13-114E)

- Nucleosides, 100× (Millipore, cat. no. ES-008-D)

- Penicillin/streptomycin (Invitrogen, cat. no. 15140-163)

- Fungizone (Invitrogen, cat. no. 15290-018)

- 50 mM 2-mercaptoethanol (Invitrogen, cat. no. 31350-010)

- Basic fibroblast growth factor (Peprotech cat. no. 100-18B)

(see REAGENT SETUP)

- $0.25 \%$ (wt/vol) Trypsin/EDTA (Invitrogen, cat. no. 25200-056)

- $0.05 \%$ (wt/vol) Trypsin/EDTA (Invitrogen, cat. no. 25300-054)

- Polybrene (10 $\mathrm{mg} \mathrm{ml}^{-1}$, Millipore, cat. no. TR-1003-G)

- FuGENE 6 transfection reagent (Roche Applied Science, cat. no. $11988387001)$
- DMSO (Sigma, cat. no. D4540)

- Human dermal fibroblast (HDF) medium (see REAGENT SETUP)

- HFF expansion medium (see REAGENT SETUP)

- RM + medium (see ref. 22)

- Human ES cell (HUES) medium (see REAGENT SETUP) EQUIPMENT

- Class-II cabinet with aspirator for tissue culture (Telstar Bio-II-A)

- Class-II cabinet with aspirator for tissue culture and space for stereomicroscope (Telstar Bio-II-A/G)

- Aspirator tube assembly (Sigma, cat. no. A5177)

- Stereomicroscope (Olympus SZX12, Olympus)

- Low-end color video camera (JVC TKC1481BEG, JVC)

- Low-end 8-inch LCD display (BOMAN TV304)

- Inverted tissue culture microscope with phase contrast and epifluorescence, with $\times 5, \times 10, \times 20$ and $\times 40$ objectives (Leica DMIL, Leica)

- Thermostatized tissue culture centrifuge and swinging rotor with adapters for $15-\mathrm{ml}$ and $50-\mathrm{ml}$ tubes and microplates (Beckman Coulter Allegra X-12R centrifuge with SX4750A rotor, Beckman Coulter)

- High-speed centrifuge and swinging rotor (Beckman Coulter Avanti J-30I centrifuge with JS-24.38 rotor, Beckman Coulter)

- Cell culture incubator set at $37^{\circ} \mathrm{C}, 5 \% \mathrm{CO}_{2}$ (REVCO, cat. no. RCO3000D-9-VBC)

- Cell culture incubator set at $32^{\circ} \mathrm{C}, 5 \% \mathrm{CO}_{2}$ (REVCO, cat. no. RCO3000D-9-VBC)

- Cell culture incubator set at $37^{\circ} \mathrm{C}, 5 \% \mathrm{CO}_{2}$ and $5 \% \mathrm{O}_{2}$ (REVCO, cat. no. RTG5000D-9-VBC)

- Microcentrifuge (Eppendorf 5424, Eppendorf)

- Straight standard forceps (Fine Science Tools, cat. no. 11000-25)

- Dumont no. 5 forceps (Fine Science Tools, cat. no. 11251-20)

- Scalpel handle and disposable blades (Fine Science Tools, cat. nos. 10003-12 and 10010-00)

- Tissue culture dish, 100 and $150 \mathrm{~mm}$

- Tissue culture flasks, T75 and T150

- Tissue culture plates, six-well

- Conical tubes, 15 and $50 \mathrm{ml}$

- Screw-cap microcentrifuge tubes (Sarstedt, cat. no. 72.692.005)

- Polyallomer centrifuge tubes, $13 \times 51 \mathrm{~mm}$ (Beckman, cat. no. 326819)

- Cover slips

- Stripper micropipette (Mid Atlantic, cat. no. MXL3-STR)

- Stripper tips, $150 \mu \mathrm{m}$

- Cryo $1{ }^{\circ} \mathrm{C}$ Freezing Container, 'Mr. Frosty' (Nalgene, cat. no. 5100-0001)

- Slide flask (Nunc, cat. no. 170920)

- Bottle-top filter system $0.22 \mu \mathrm{m}, 500 \mathrm{ml}$ (Millipore, cat. no. SCGPU05RE)

- Filter, Mille-HV PVDF (polyvinylidene fluoride) $(0.45 \mu \mathrm{m}$, Millipore, cat. no. SLHV033RS)

\section{REAGENT SETUP}

Lentiviral vectors The pRRLsin 18.ppt.SFFVFANCAIRESeGFP.Wpre LV (SFFV-FANCAieGFP-LV) has been described ${ }^{23}$. Packaging and envelope vectors (pMD2.VSV.G, pMDLg-pRRE and pRSV-Rev) were kindly provided by L. Naldini (San Raffaele Telethon Institute for Gene Therapy-'Vita-Salute San Raffaele' University Medical School, Milano, Italy).

Retroviral vectors pMSCV-based retroviral vectors expressing FLAG-tagged OCT4, SOX2, KLF4 and c-MYC ${ }^{\mathrm{T} 58 \mathrm{~A}}$ are available from Addgene (plasmids 20072, 20073, 20074 and 20075, respectively).

Basic fibroblast growth factor (bFGF) Spin the bFGF vial briefly to bring the contents down. Resuspend the contents of the vial with $10 \mathrm{ml}$ of $0.2 \%$ 


\section{BOX 1 | GENERATION OF A STOCK OF IRRADIATED HFF}

1. Expand the original vial of HFFs (ATCC cat. no. CRL-2429) following ATCC's directions to generate a stock of frozen HFFs at passage $7\left(2.5 \times 10^{6} \mathrm{HFFs}\right.$ per frozen vial).

2. Thaw one vial of passage-7 HFFs into a 150-mm dish with HFF expansion medium.

3. After $8 \mathrm{~d}$, aspirate the medium, wash with PBS and trypsinize the cells with $2 \mathrm{~mL}$ of $0.25 \%$ trypsin/EDTA for 5 min at $37^{\circ} \mathrm{C}$. Split the cells in the ratio of 1:6 into $6 \times 150$-mm dishes with HFF expansion medium.

4. After $8 \mathrm{~d}$, trypsinize and split the cells again at a 1:6 ratio to generate $36 \times 150$-mm dishes with HFF expansion medium.

5. After $8 d$, trypsinize and collect the cells from all 36 dishes:

5.1. Working in groups of six dishes, aspirate the medium, wash twice with PBS and add $2 \mathrm{~mL}$ of $0.25 \%$ trypsin/EDTA to each plate. Incubate for $5 \mathrm{~min}$ at $37^{\circ} \mathrm{C}$ and collect the cells of each plate with $6 \mathrm{ml}$ of HFF expansion medium.

5.2. Collect the cell suspension of six dishes into a $50-\mathrm{ml}$ conical tube ( $48 \mathrm{ml}$ total).

5.3. Centrifuge the six $50-\mathrm{ml}$ conical tubes at $335 \mathrm{~g}$ for $5 \mathrm{~min}$ at $25^{\circ} \mathrm{C}$ and discard the supernatant.

5.4. Resuspend the cell pellet of each tube with $10 \mathrm{~mL}$ of HFF expansion medium and combine three of them to finally have two $50-\mathrm{ml}$ conical tubes each containing $30 \mathrm{ml}$ of cell suspension.

6. Irradiate the cell suspensions at $45 \mathrm{~Gy}$.

7. Count the number of viable cells.

8. Centrifuge at $335 \mathrm{~g}$ for $10 \mathrm{~min}$ at $25^{\circ} \mathrm{C}$ and discard the supernatant.

9. While centrifuging, prepare the necessary amount of freezing medium ( $90 \%$ ( $\mathrm{vol} / \mathrm{vol}) \mathrm{FCS}, 10 \%$ ( $\mathrm{vol} / \mathrm{vol}) \mathrm{DMS} 0)$, considering $1 \mathrm{ml}$ for every $4 \times 10^{6}$ cells, and put it on ice.

10. In addition, while centrifuging, prepare the necessary number of cryovials, considering one vial for every $4 \times 10^{6}$ cells, and put them on ice.

11. Working on ice, resuspend the cells with the pre-chilled freezing medium at a cell concentration of $4 \times 10^{6}$ cells per $\mathrm{ml}$ and aliquot $1 \mathrm{ml}$ of cell suspension into each cryovial.

12. Freeze the cells overnight at $-80^{\circ} \mathrm{C}$ using a cryo $1{ }^{\circ} \mathrm{C}$ freezing container, before transferring the frozen vials to liquid $\mathrm{N}_{2}$ for long-term storage.

13. Expect $50-60$ vials of irradiated HFFs.

(wt/vol) HSA in PBS. The final concentration of bFGF is $100 \mu \mathrm{g} \mathrm{ml}^{-1}$. Prepare 50- and $100-\mu \mathrm{l}$ aliquots in screw-cap microcentrifuge tubes and store at $-20^{\circ} \mathrm{C}$ for up to 6 months. Avoid more than three freeze-thaw cycles. HDF medium. DMEM containing 10\% FBS (vol/vol), 2 mM GlutaMAX, $50 \mathrm{U} \mathrm{ml}^{-1}$ penicillin and $50 \mathrm{mg} \mathrm{ml}^{-1}$ streptomycin. To prepare $500 \mathrm{ml}$ of HDF medium, remove $60 \mathrm{ml}$ of DMEM from a new bottle and add $50 \mathrm{ml}$ FBS, $5 \mathrm{ml}$ GlutaMAX and $5 \mathrm{ml}$ penicillin/streptomycin. There is no need to filter the medium. Store at $4{ }^{\circ} \mathrm{C}$ in the dark and use within 1 month. HFF expansion medium. IMDM containing $10 \% \mathrm{FBS}$ ( $\mathrm{vol} / \mathrm{vol}$ ), $50 \mathrm{U} \mathrm{ml}^{-1}$ penicillin and $50 \mathrm{mg} \mathrm{ml}^{-1}$ streptomycin. To prepare $500 \mathrm{ml}$ of HFF expansion medium, remove $55 \mathrm{ml}$ of IMDM from a new bottle and add $50 \mathrm{ml} \mathrm{FBS}$ and
$5 \mathrm{ml}$ penicillin/streptomycin. There is no need to filter the medium. Store at $4^{\circ} \mathrm{C}$ in the dark and use within 1 month.

HUES medium. KO-DMEM containing 10\% KO-SR (vol/vol), 0.5\% HSA (wt/vol), $2 \mathrm{mM}$ GlutaMAX, $100 \mu \mathrm{M}$ nonessential amino acids, $1 \times$ nucleosides, $100-\mu \mathrm{M} 2$-mercaptoethanol, $50 \mathrm{U} \mathrm{ml}^{-1}$ penicillin, $50 \mathrm{mg} \mathrm{ml}^{-1}$ streptomycin and $10 \mathrm{ng} \mathrm{ml}^{-1} \mathrm{bFGF}$. To prepare $600 \mathrm{ml}$, pour the entire contents of a 500 -ml bottle of KO-DMEM into a 500-ml $0.22 \mu \mathrm{m}$ filtration unit and add $60 \mathrm{ml} \mathrm{KO-SR,} 15 \mathrm{ml}$ of 20\% (wt/vol) HSA, $6 \mathrm{ml}$ GlutaMAX, $6 \mathrm{ml}$ nonessential aminoacids, $6 \mathrm{ml}$ of $100 \times$ nucleosides, $6 \mathrm{ml}$ penicillin/ streptomycin, $600 \mu \mathrm{l} 2$-mercaptoethanol and $60 \mu \mathrm{l}$ bFGF. Filter the medium and store in the dark at $4{ }^{\circ} \mathrm{C}$ for up to 1 week.

\section{BOX 2 | COATING DISHES WITH MATRIGEL}

To prepare the $\mathrm{Mg}$ solution (150 $\mathrm{ml}$ of $\mathrm{Mg}$ in the ratio of $1: 15$ in $\mathrm{KO}-\mathrm{DMEM}$ ):

1. Put one vial of $\mathrm{Mg}$ on ice in a cold room or large fridge to thaw overnight.

2. Put a bottle containing $140 \mathrm{ml}$ of $\mathrm{KO}$-DMEM to chill on ice overnight in a cold room or large fridge.

3. The next morning, put a $10-\mathrm{ml}$ serological pipette to chill at $-20{ }^{\circ} \mathrm{C}$ for $1 \mathrm{~h}$.

4. Working on ice inside the tissue culture hood, use the pre-chilled $10-\mathrm{ml}$ pipette to collect the contents of the $\mathrm{Mg}$ vial and add it to the KO-DMEM bottle.

5. Wash the vial several times with the $\mathrm{Mg} / \mathrm{KO}$-DMEM solution to recover any remains.

6. Immediately store the $\mathrm{Mg}$ solution in the dark at $4{ }^{\circ} \mathrm{C}$.

To coat dishes with $\mathrm{Mg}$ :

1. Take the Mg solution and put it on ice.

2. Add enough $\mathrm{Mg}$ solution to cover the dish/well surface, i.e., $5 \mathrm{ml}$ for $100-\mathrm{mm}$ dishes and $1 \mathrm{ml}$ for a well of a six-well plate.

3. Immediately put the remaining $\mathrm{Mg}$ solution back at $4{ }^{\circ} \mathrm{C}$.

4. Swirl the dishes/plates to ensure that the bottom is completely covered with the $\mathrm{Mg}$ solution.

5. Incubate the dishes/plates overnight at $4{ }^{\circ} \mathrm{C}$ or for $4 \mathrm{~h}$ at room temperature.

6. Immediately before plating the cells, aspirate the $\mathrm{Mg}$ solution and wash with cold KO-DMEM. 
PROTOCOL

\section{PROCEDURE}

\section{Establishment of patients' primary cell cultures $\bigcirc$ TIMING 6 weeks}

1| Arrange for a patient's $\sim 4-\mathrm{mm}$ skin punch biopsy to be taken by an appropriately trained physician.

2) Place the biopsy sample in a $50-\mathrm{ml}$ conical tube containing $\sim 25 \mathrm{ml}$ of sterile PBS at room temperature $\left(20-25{ }^{\circ} \mathrm{C}\right)$ for shipment to the laboratory and delivery within $24 \mathrm{~h}$ of sample retrieval.

3| Inside a tissue culture hood, aspirate the PBS and replace with 15-20 ml of PBS containing 10x penicillin/streptomycin (500 $\mathrm{U} \mathrm{ml}^{-1}$ penicillin and $500 \mu \mathrm{g} \mathrm{ml}^{-1}$ streptomycin) and 10x Fungizone (25 $\mathrm{g} \mathrm{ml}^{-1}$ amphotericin B). Leave the sample tube inside the hood at room temperature for $15 \mathrm{~min}$, with occasional mixing by inverting the tube.

$\triangle$ CRITICAL STEP This and all subsequent steps should be carried out in a tissue culture hood.

4| Repeat Step 3 twice again, and finally, wash the biopsy sample with 15-20 ml of PBS (without antibiotics) for 15 min.

5| Using sterile forceps, transfer the biopsy piece onto the lid of a 100-mm tissue culture plate placed upside down. Cut away any subdermal fat tissue using a scalpel with a sterile blade, leaving the epidermis and dermal tissue.

6| Using sterile Dumont no. 5 forceps and a scalpel with a sterile blade, cut the biopsy specimen into 30-40 pieces of $\sim 0.5 \mathrm{~mm}$ size.

7| Transfer 8-10 pieces to each of the four 60-mm tissue culture dishes, epidermal side up, trying to space the pieces evenly apart onto the surface of the dish. Two dishes will be used for establishing primary cultures of dermal fibroblasts and the other two dishes to generate epidermal keratinocytes.

8| Leave the dishes with their lids off under the tissue culture hood for $2 \mathrm{~min}$ (or until the biopsy pieces start becoming matte).

$\Delta$ CRITICAL STEP Do not let the skin pieces dry up too much or cell outgrowth will fail. Conversely, if the pieces are not dry enough, they will float and no cellular outgrowth will be obtained. With some practice, it should be easy to attain the optimal degree of dryness in most of the biopsy pieces in any given dish. Until then, sterile cover slips can be used in two of the dishes (one for fibroblasts and one for keratinocytes) to keep the biopsy pieces in contact with the bottom of the dish. We feel that this results in less robust cellular outgrowths but requires little earlier experience. For this purpose, place the pieces close to one another on one side of the $60-\mathrm{mm}$ dish in Step 7, so that they will be covered by a $20 \times 20-\mathrm{mm}$ cover slip, carefully lay a sterile cover slip on top of the pieces while they are wet, and use a micropippette set to $100 \mu$ to fill the space between the cover slip and the bottom of the dish with cold medium (HDF medium for the fibroblasts dish or $\mathrm{RM}+$ medium for the keratinocytes dish) by capillary action.

9| Add $1 \mathrm{ml}$ of pre-warmed medium to each dish (HDF medium for fibroblasts dishes or RM + medium for keratinocytes dishes) and transfer them carefully to a cell culture incubator set at $37{ }^{\circ} \mathrm{C}, 5 \% \mathrm{CO}_{2}$. Leave the dishes undisturbed until next morning. For dishes with cover slips, add $5 \mathrm{ml}$ of pre-warmed medium to each dish (HDF medium for the fibroblasts dish or $\mathrm{RM}+$ medium for the keratinocytes dish), put them into the cell culture incubator set at $37{ }^{\circ} \mathrm{C}, 5 \% \mathrm{CO}_{2}$, and go directly to Step 11.

? TROUBLESHOOTING

10| Add $4 \mathrm{ml}$ of pre-warmed medium to each dish (HDF medium for fibroblasts dishes or RM + medium for keratinocytes dishes). Recover any biopsy pieces that may float free and process them as in Steps 7-9. Continue processing the dishes for keratinocyte derivation as detailed in reference 22. Return the fibroblasts dishes to the incubator.

11| Incubate at $37^{\circ} \mathrm{C}, 5 \% \mathrm{CO}_{2}$, changing medium once every week.

? TROUBLESHOOTING

12| After 3-4 weeks, fibroblasts outgrowing from the biopsy pieces will cover most of the dish. Aspirate the medium and add $5 \mathrm{ml}$ of PBS. If a cover slip was used, lift it using a sterile micropipette tip (with care to avoid detaching the biopsy pieces), flip it and place it upside down on the same dish, away from the still attached biopsy pieces.

13. Aspirate the PBS and add $1 \mathrm{ml}$ of pre-warmed $0.25 \%$ trypsin/EDTA. Incubate for $5 \mathrm{~min}$ at $37^{\circ} \mathrm{C}$. Check under the microscope whether the fibroblasts have rounded up and begin to detach from the dish. 
14| Add $5 \mathrm{ml}$ of pre-warmed HDF medium to the dish and pipette up and down to completely detach and dissociate the cells. Be careful not to pipette the medium down directly onto the biopsy pieces to avoid detaching them. Collect the medium containing the dissociated fibroblasts from both dishes in a $15-\mathrm{ml}$ conical tube.

15| Add $5 \mathrm{ml}$ of pre-warmed HDF medium to the dish. If a cover slip was used, it can now be discarded. Most of the biopsy pieces should still be attached to the dish. After 1-2 weeks, new fibroblast outgrowths will have covered the dish. Trypsinize and freeze these fibroblasts as explained in Steps 19-22, to generate a backup stock of passage 0 fibroblasts.

16| Centrifuge the cells from Step 14 at 335g (1,200 r.p.m. in a Beckman Coulter Allegra X-12R centrifuge with SX4750A rotor) at $25^{\circ} \mathrm{C}$ for 5 min and discard the supernatant.

17| Resuspend the cells using $5 \mathrm{ml}$ of pre-warmed HDF medium and plate into a T-75 flask containing $10 \mathrm{~mL}$ of HDF medium (passage 1). Incubate at $37{ }^{\circ} \mathrm{C}, 5 \% \mathrm{CO}_{2}$ and $5 \% \mathrm{O}_{2}$.

18 When the cells reach $80 \%$ confluence, aspirate the medium, wash with PBS, trypsinize with $2.5 \mathrm{ml}$ of $0.25 \%$ trypsin/ EDTA for 5 min at $37{ }^{\circ} \mathrm{C}$, resuspend the cells with $10 \mathrm{ml}$ of HDF medium and plate into two T-150 flasks containing $30 \mathrm{~mL}$ of HDF medium (passage 2). Incubate at $37{ }^{\circ} \mathrm{C}, 5 \% \mathrm{CO}_{2}$ and $5 \% \mathrm{O}_{2}$.

19| After 7-10 d, or when the cells have reached $80 \%$ confluence, aspirate the medium, wash with PBS, trypsinize with $5 \mathrm{ml}$ of $0.25 \%$ trypsin/EDTA for $5 \mathrm{~min}$ at $37{ }^{\circ} \mathrm{C}$, resuspend the cells with $20 \mathrm{ml}$ of HDF medium and collect the medium from both flasks in a $50 \mathrm{ml}$ conical tube.

20| Pipette $10 \mu \mathrm{l}$ of the cell suspension for counting the number of viable fibroblasts with trypan blue using a hemocytometer. Centrifuge the cell suspension at $335 \mathrm{~g}$ at $25^{\circ} \mathrm{C}$ for $5 \mathrm{~min}$ and discard the supernatant.

21 Resuspend the cells with the necessary volume of ice-cold, freshly prepared $90 \%$ (vol/vol) FCS and 10\% (vol/vol) DMSO to yield a concentration of $2 \times 10^{6}$ viable cells per ml. Immediately aliquot the cell suspension at $1 \mathrm{ml}$ per cryovial.

22| Freeze the cryovials overnight at $-80^{\circ} \mathrm{C}$ using a cryo $1^{\circ} \mathrm{C}$ freezing container. Transfer the frozen vials to $\mathrm{N}_{2}$ cryostorage to generate a working stock of passage 2 fibroblasts.

PAUSE POINT Properly frozen cells can be stored indefinitely in liquid $\mathrm{N}_{2}$.

\section{Production of gene correction lentiviruses TIMING $7 \mathrm{~d}$}

23| Day 1: Thaw a cryovial of 293T cells and transfer the contents into a $15-\mathrm{ml}$ conical tube containing $7.5 \mathrm{ml}$ of HDF medium. Wash the cryovial by adding $1.5 \mathrm{ml}$ of HDF medium and combine this with the cell suspension in the 15 - $\mathrm{ml}$ conical tube. Centrifuge the cells at $600 \mathrm{~g}$ at $25^{\circ} \mathrm{C}$ for $7 \mathrm{~min}$ and discard the supernatant.

24| Resuspend the cells with $5 \mathrm{ml}$ of HDF medium and transfer to a $50-\mathrm{ml}$ conical tube, count the cell number and add the necessary volume of HDF medium to give a cell concentration of $4 \times 10^{5}$ cells per $\mathrm{ml}$.

25| Plate $2 \times 10^{6} 293 \mathrm{~T}$ cells ( $5 \mathrm{ml}$ of cell suspension) into each of the three $100-\mathrm{mm}$ dishes containing $5 \mathrm{ml}$ of HDF medium.

26| Incubate at $37{ }^{\circ} \mathrm{C}, 5 \% \mathrm{CO}_{2}$ for $2 \mathrm{~d}$ or until the cells have reached $80-90 \%$ confluence.

27| Day 3: From each of the three 100-mm dishes, aspirate the medium, wash with PBS, trypsinize with $2.5 \mathrm{ml} 0.25 \%$ trypsin/EDTA for $3 \mathrm{~min}$ at $37^{\circ} \mathrm{C}$ and resuspend with $7.5 \mathrm{ml}$ of HDF medium. Transfer the cell suspensions (total volume of $30 \mathrm{ml}$ ) into a $50-\mathrm{ml}$ conical tube, count the cell number and add the necessary volume of HDF medium to give a cell concentration of $2 \times 10^{6}$ cells per $\mathrm{ml}$.

28| Plate $18 \times 10^{6} 293 \mathrm{~T}$ cells ( $9 \mathrm{ml}$ of cell suspension) into each of the three $150-\mathrm{mm}$ dishes containing $16 \mathrm{ml}$ of HDF medium. Incubate at $37{ }^{\circ} \mathrm{C}, 5 \% \mathrm{CO}_{2}$ overnight.

$\triangle$ CRITICAL STEP The cell density of 293T cells is critical for efficient transfection for lentiviral production (Fig. 1). According to us, an optimal cell density of $80 \%$ is achieved after $8-12 \mathrm{~h}$ of incubation following this protocol. Fine-tuning of this timing may be required for each specific laboratory. 
29| Day 4: The next morning, or when the cells have reached $80 \%$ confluence, aspirate the medium from 293T cells and replace with $15 \mathrm{ml}$ of fresh HFF medium. Incubate at $37{ }^{\circ} \mathrm{C}, 5 \% \mathrm{CO}_{2}$ for $2 \mathrm{~h}$.

! CAUTION Vesicular stomatitis virus G (VSV-G)-pseudotyped lentiviruses readily infect human cells. Production, concentration and use of VSV-G-pseudotyped lentiviruses must be performed under BL2 biosafety containment.

30| Working under a tissue culture hood, prepare the DNA transfection mix in a $15-\mathrm{ml}$ conical tube by mixing

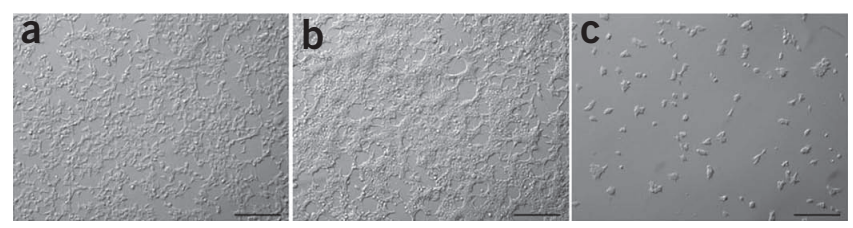

Figure 1 | Optimal density of 293T cells for transfection. (a) Cultures at optimal cell density for transfection are at $~ 80 \%$ confluence, with homogeneously distributed cells. (b) Slightly overgrown cultures display large areas of very crowded cells and are not suitable for transfection.

(c) Cells seeded at low density tend to form clusters and are also unsuitable for transfection. Scale bars $=250 \mu \mathrm{m}$. together the following amounts of the four plasmids: $96 \mu \mathrm{g}$ of SFFV-FANCAieGFP-LV, $48 \mu \mathrm{g}$ of pMDLg-pRRE, $20.25 \mu \mathrm{g}$ of pRSV-Rev and $48 \mu \mathrm{g}$ of pMD2.VSV.G. Adjust the volume to $3.375 \mathrm{ml}$ with $0.1 \times$ Tris-EDTA buffer.

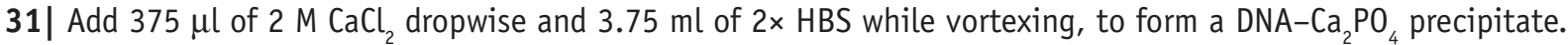

32 Add $2.5 \mathrm{ml}$ of the mixture to each $150-\mathrm{mm}$ dish in a dropwise manner. Swirl the dishes to distribute the mixture evenly across the entire dish surface. Incubate at $37{ }^{\circ} \mathrm{C}, 5 \% \mathrm{CO}_{2}$ for $16 \mathrm{~h}$.

33| Day 5: Replace the medium with $15 \mathrm{ml}$ of fresh HFF medium. Incubate at $37{ }^{\circ} \mathrm{C}, 5 \% \mathrm{CO}_{2}$ for $24 \mathrm{~h}$. Start in parallel with Step 39 for the eventual titration of the lentiviral stocks.

34| Day 6: Collect the medium of each dish (containing lentiviral particles) and filter through $0.45-\mu \mathrm{m}$ filter units to make cell-free infective supernatants.

35| Add $15 \mathrm{ml}$ of fresh HFF medium to each dish. Incubate at $37^{\circ} \mathrm{C}, 5 \% \mathrm{CO}_{2}$ for $24 \mathrm{~h}$.

36| Centrifuge lentivirus-containing media at $80,000 \mathrm{~g}$ (21,500 r.p.m. in a Beckman Coulter Avanti J-30I centrifuge with JS-24.38 rotor) at room temperature for $2 \mathrm{~h}$. Discard the supernatant and resuspend the viral pellet in $0.5 \mathrm{ml}$ of HFF medium with gentle shaking. Allow the pellet to dissolve overnight at $4^{\circ} \mathrm{C}$.

37| Day 7: Collect the medium of each dish (containing lentiviral particles) again and process them as for day 6.

38| If necessary, complete the resuspension of the viral pellet by pipetting up and down through a $100-\mu$ micropipette tip. Divide the lentiviral preparation into $30-\mu \mathrm{l}$ aliquots in screw-cap microcentrifuge tubes and store at $-80{ }^{\circ} \mathrm{C}$, to generate a stock of concentrated SFFV-FANCAieGFP-LV.

PAUSE POINT Concentrated VSV-G-pseudotyped lentiviral stocks can be stored at $-80^{\circ} \mathrm{C}$ for several months without loss of infectivity. Avoid repeated freeze-thaw cycles.

\section{Titration of gene correction lentiviral stocks $\bigcirc$ TIMING $9 \mathrm{~d}$}

39| Thaw one vial of HT1080 cells into a $100-\mathrm{mm}$ dish with HDF medium. Incubate at $37{ }^{\circ} \mathrm{C}, 5 \% \mathrm{CO}_{2}$. Passage cells when they reach $90 \%$ confluence at a 1:5 ratio.

40| When ready to begin the titration of lentiviral stocks, trypsinize a 100-mm dish of HT1080 cells, count the cell number and adjust the concentration to $7 \times 10^{4}$ cells per $\mathrm{ml}$.

41| Add $0.5 \mathrm{~mL}$ of HT1080 cell suspension ( $3.5 \times 10^{4}$ cells) to each well of a 24-well plate.

42 Immediately after Step 41, thaw one vial of the lentiviral stock and prepare six serial dilutions in HDF medium, from $10^{-2}$ to $10^{-7}$, in final volumes of $\sim 75 \mu \mathrm{l}$.

43 Add $20 \mu$ l of virus dilution to each well of the first three rows of wells, so that each column will contain triplicate infections of any given dilution. The fourth row of wells will be uninfected controls. Incubate at $37{ }^{\circ} \mathrm{C}, 5 \% \mathrm{CO}_{2}$ overnight.

44| Replace the medium with fresh HDF medium. Incubate at $37^{\circ} \mathrm{C}, 5 \% \mathrm{CO}_{2}$ for $4 \mathrm{~d}$. 
45 Aspirate medium, wash with PBS, trypsinize cells with $100 \mu \mathrm{l}$ of $0.25 \%$ trypsin/EDTA for 5 min at $37{ }^{\circ} \mathrm{C}$ and collect cells of each well with $400 \mu \mathrm{l}$ of HDF medium in screw-cap microcentrifuge tubes. Determine the percentage of green fluorescent protein (GFP)-positive cells in each tube by flow cytometry. Calculate the lentiviral biological titer (transducing units per $\mathrm{ml}$ ) according to the following formula: Titer $\left(\mathrm{TU} \mathrm{ml}^{-1}\right)=$ [Percentage of GFP+ cells] $(\%) \times\left[3.5 \times 10^{4}\right]$ (number of cells) $\times$ $\left[1 / 20 \times 10^{-3}\right]\left(\mathrm{ml}^{-1}\right) \times[1 /$ dilution $]$. Titers should be in the range of $10^{8} \mathrm{TU} \mathrm{ml}^{-1}$ in the concentrated supernatants. ? TROUBLESHOOTING

\section{Gene therapy of patients' somatic cells $\bigcirc$ TIMING $7 \mathrm{~d}$}

46| Day 1: Thaw one vial of passage 2 fibroblasts into six wells of a six-well plate with HDF medium. Incubate at $37^{\circ} \mathrm{C}$, $5 \% \mathrm{CO}_{2}$ and $5 \% \mathrm{O}_{2}$ for $24 \mathrm{~h}$ (passage 3 ).

$\triangle$ CRITICAL STEP For best reprogramming efficiency, initiate Steps 46 and 56 on the same day, so that the availability of genetically corrected fibroblasts and of reprogramming retroviruses coincides.

47| Day 2: Cell confluence should be around 40-50\%. Aspirate the medium and add $1 \mathrm{ml}$ of fresh HDF medium containing $5 \mu \mathrm{g} \mathrm{ml}^{-1}$ polybrene. Incubate at $37{ }^{\circ} \mathrm{C}, 5 \% \mathrm{CO}_{2}$ and $5 \% \mathrm{O}_{2}$ for $1 \mathrm{~h}$.

48| Thaw one vial of concentrated SFFV-FANCAieGFP-LV lentiviral supernatant at room temperature for several minutes. Stir vigorously by vortex before use.

49| Add $5 \mu \mathrm{l}$ of LV stock to each of the two wells of the six-well plate and $10 \mu \mathrm{l}$ to two other wells. Mix the lentiviruses and the medium by pipetting up and down several times. Leave two wells with no virus as untransduced controls. Incubate at $37{ }^{\circ} \mathrm{C}, 5 \% \mathrm{CO}_{2}$ and $5 \% \mathrm{O}_{2}$ overnight.

50| Day 3: Aspirate the medium to all wells and add $2 \mathrm{ml}$ of HDF medium. Incubate at $37{ }^{\circ} \mathrm{C}, 5 \% \mathrm{CO}_{2}$ and $5 \% \mathrm{O}_{2}$ for $2 \mathrm{~d}$.

51| Day 5: Estimate the transduction efficiency in wells infected with 5 or $10 \mu \mathrm{l}$ of SFFV-FANCAieGFP-LV stock by visualizing GFP-positive cells under a fluorescence microscope (Fig. 2) and comparing cell survival with untransduced wells. Select the infected wells with the best transduction/survival ratio, along with uninfected cells, for reprogramming. LV-transduced fibroblasts can also be expanded for additional analyses and stored as frozen vials; however, reprogramming is more efficient if performed immediately after LV transduction.

? TROUBLESHOOTING

52| Day 6: Aspirate the medium from the selected wells (transduced and untransduced), wash with PBS and trypsinize with $0.5 \mathrm{ml}$ of $0.05 \%$ trypsin/EDTA for $5 \mathrm{~min}$ at $37{ }^{\circ} \mathrm{C}$.

53 Add $2 \mathrm{ml}$ of HDF medium to collect the cells into a $15-\mathrm{ml}$ conical tube. Add 1 more $\mathrm{ml}$ of HDF medium to the well to recover any remaining cells and combine it with the other $2 \mathrm{ml}$. Count the cell number and adjust the concentration to $1 \times 10^{5}$ cells per $\mathrm{ml}$.

54| Plate $1 \mathrm{ml}$ of the cell suspension $\left(1 \times 10^{5}\right.$ cells) on each well of a six-well plate containing $1 \mathrm{ml}$ of HDF medium (passage 4). It is advisable to plate transduced and untransduced fibroblasts on different wells of the same plate so that they will be processed in parallel. Plate three wells for each condition: two for reprogramming (with OSKM and OSK) and one as a negative control.

55 Incubate at $37{ }^{\circ} \mathrm{C}, 5 \% \mathrm{CO}_{2}$ and $5 \% \mathrm{O}_{2}$ for $24 \mathrm{~h}$. The part of the procedure using these cells continues at Step 70.

\section{Production of reprogramming retroviruses TIMING $7 \mathrm{~d}$} 56| Day 1: Thaw one vial of Phoenix Amphotropic cells onto a $100-\mathrm{mm}$ dish with $\mathrm{HDF}$ medium. Incubate at $37^{\circ} \mathrm{C}, 5 \% \mathrm{CO}_{2}$ for $3 \mathrm{~d}$.

57| Day 4: Aspirate the medium, wash with PBS, trypsinize cells with $0.05 \%$ trypsin/EDTA for 3 min at $37{ }^{\circ} \mathrm{C}$ and collect cells with $10 \mathrm{ml}$ of HDF medium into a $50-\mathrm{ml}$ conical tube.

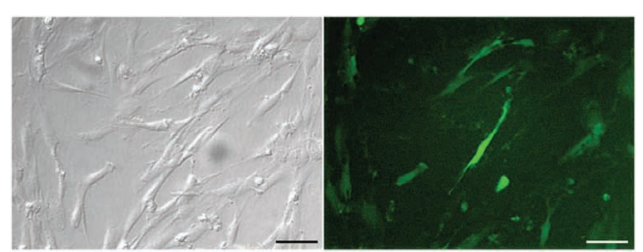

Figure 2 | Human dermal fibroblasts transduced with correcting lentivirus. Passage-3 fibroblasts derived from a skin biopsy of an FA patient at $3 \mathrm{~d}$ after transduction with concentrated SFFV-FANCAieGFP-LV. The left panel shows modulation contrast microscope image. The right panel shows fluorescence of the same microscope field in transduced cells, owing to the GFP expressed after an IRES element of the correcting lentiviral vector. Scale bars $=100 \mu \mathrm{m}$. 
PROTOCOL

58| Count the cell number and adjust the concentration to $0.9 \times 10^{6}$ cells per $\mathrm{ml}$ with HDF medium.

59| Add $5 \mathrm{ml}$ of cell suspension $\left(4.5 \times 10^{6}\right.$ cells $)$ to each of four $100-\mathrm{mm}$ dishes containing $5 \mathrm{ml}$ of HDF medium. Incubate at $37{ }^{\circ} \mathrm{C}, 5 \% \mathrm{CO}_{2}$ for $24 \mathrm{~h}$.

60| Day 5: Prepare four sterile screw-cap microcentrifuge tubes each containing $873 \mu$ of PBS and $27 \mu$ L FuGENE 6 transfection reagent.

61| Vortex the mixture and leave the tubes at room temperature for 5 min.

62 Add $9 \mu \mathrm{g}$ of retroviral vector (pMSCV-OCT4, pMSCV-SOX2, pMSCV-KLF4 or pMSCV-c-MYC) to each tube, vortex the mixture and incubate at room temperature for $30 \mathrm{~min}$.

63 Add the contents of each tube to each of the four $100-\mathrm{mm}$ dishes, and rock the dishes back and forth to distribute the mixture evenly across the entire dish surface. Incubate at $37{ }^{\circ} \mathrm{C}, 5 \% \mathrm{CO}_{2}$ for $24 \mathrm{~h}$.

64| Day 6: Aspirate transfection media and replace it with $7.5 \mathrm{ml}$ of HDF medium. Add the medium carefully, as cells tend to detach from the dish at this stage.

65 Incubate the plates at $32{ }^{\circ} \mathrm{C}, 5 \% \mathrm{CO}_{2}$ for $24 \mathrm{~h}$. Viruses are more stable at $32{ }^{\circ} \mathrm{C}$; hence, higher retroviral titers are obtained by incubating the plates at this temperature.

66| Day 7: Put the microplate adapters into the tissue culture centrifuge and spin it at $1,500 \mathrm{~g}$ to warm it up to $32{ }^{\circ} \mathrm{C}$.

67| Collect the medium of each dish (containing retroviral particles) into a 15-ml conical tube.

68 Add $7.5 \mathrm{ml}$ of HDF medium to the dishes and place them back carefully in the incubator at $32{ }^{\circ} \mathrm{C}, 5 \% \mathrm{CO}_{2}$ for $24 \mathrm{~h}$ for a second collection of retroviral supernatants.

$69 \mid$ Filter the retrovirus-containing media through $0.45-\mu \mathrm{m}$ filter units to make cell-free infective supernatants, and add $3.75 \mu \mathrm{l}$ of $10 \mathrm{mg} \mathrm{ml}^{-1}$ polybrene (final concentration $5 \mu \mathrm{g} \mathrm{ml}^{-1}$ ). Combine $3 \mathrm{ml}$ of each retroviral supernatant to generate OSKM mix (positive control). Combine $3 \mathrm{~mL}$ of OCT4, SOX2 and KL4 retroviruses to generate OSK mix. Proceed immediately to Step 70.

\section{Reprogramming genetically corrected somatic cells $\bigcirc$ TIMING 4-8 weeks}

70| Day 1: Aspirate the medium of the fibroblast plates from Step 55 and add $4 \mathrm{~mL}$ of OSKM or OSK mix from Step 69 to each well to be reprogrammed. Add $4 \mathrm{ml}$ of HDF medium to negative control wells.

71| Centrifuge the plate(s) at $750 \mathrm{~g}$ for $45 \mathrm{~min}$ at $32^{\circ} \mathrm{C}$.

! CAUTION Amphotropic retroviruses encoding oncogenes must be produced and used under BL2 biosafety containment.

72 Leave the retroviral-containing media in the wells and incubate at $37^{\circ} \mathrm{C}, 5 \% \mathrm{CO}_{2}$ for $24 \mathrm{~h}$.

$\triangle$ CRITICAL STEP Fibroblasts grow more robustly when incubated under $5 \% \mathrm{O}_{2}$ (this is even more evident for fibroblasts from FA patients). However, for reasons that we do not fully understand yet, retroviral infection and/or reprogramming of fibroblasts appear severely impaired at $5 \% \mathrm{O}_{2}$. For this reason, incubations in the following steps should be performed at atmospheric $0_{2}$.

73| Day 2: Repeat the infection as in Steps 70-72, using the second retroviral supernatants collected in Step 68, processed as in Step 69.

74| Day 3: Aspirate the medium from the wells, add $2 \mathrm{~mL}$ of HDF medium and incubate at $37{ }^{\circ} \mathrm{C}, 5 \% \mathrm{CO}_{2}$ for $24 \mathrm{~h}$.

75 Add $5 \mathrm{ml}$ of $0.1 \%$ gelatin to each of the eight $100-\mathrm{mm}$ dishes. Swirl the dishes one by one to ensure that the gelatin solution completely spreads through the bottom of the dish. Put the dishes in the incubator at $37^{\circ} \mathrm{C}$ overnight. 
76| Day 4: Aspirate the gelatin solution from the eight 100-mm dishes and leave them under the tissue culture hood without lids to dry up completely.

77| Thaw two vials of irradiated HFFs (see Box 1 for preparation of a stock of irradiated HFFs) per each well being reprogrammed and for the negative controls. Transfer the contents of the vials into $50-\mathrm{ml}$ conical tubes containing $7.5 \mathrm{ml}$ of HDF medium per vial. Wash each of the vials with $1.5 \mathrm{~mL}$ of HDF medium and collect any remaining cells in the $50-\mathrm{ml}$ conical tubes. Centrifuge the tubes at $335 \mathrm{~g}$ for $5 \mathrm{~min}$ at $25^{\circ} \mathrm{C}$, discard the supernatant and resuspend cells with $4 \mathrm{ml}$ of HDF medium per vial thawed. Count the cell number and adjust the concentration to $8 \times 10^{5}$ cells per $\mathrm{ml}$. Leave the $50-\mathrm{ml}$ conical tubes containing the suspension of irradiated HFFs under the hood at room temperature until needed.

78| Aspirate the medium of the infected/control wells, wash with PBS and trypsinize with $0.5 \mathrm{~mL}$ of $0.05 \%$ trypsin/EDTA for $5 \mathrm{~min}$ at $37{ }^{\circ} \mathrm{C}$. Resuspend the dissociated cells adding $1.5 \mathrm{ml}$ of HDF medium and pipetting up and down with a micropipette and 1-ml tips. Transfer the cell suspension to a $15-\mathrm{ml}$ conical tube. Add $1 \mathrm{ml}$ of HDF medium to each well to recover any remaining cells and collect them into the $15-\mathrm{ml}$ conical tube.

79| Count the number of viable cells in each cell suspension and transfer $1 \times 10^{5}$ viable cells into a new 15 -ml conical tube (fibroblasts infected with OSKM and negative controls) or two new 15-mL conical tubes (fibroblasts infected with 0SK). Add $5 \mathrm{ml}$ of irradiated HFFs suspension $\left(4 \times 10^{6}\right.$ cells) to each $15-\mathrm{ml}$ conical tube. At this point, there should be eight $15-\mathrm{ml}$ conical tubes in this example: one of genetically corrected fibroblasts infected with OSKM, two of genetically corrected fibroblasts infected with OSK, one of genetically corrected fibroblasts not infected with retroviruses, one of uncorrected fibroblasts infected with OSKM, two of uncorrected fibroblasts infected with OSK and one of uncorrected fibroblasts not infected with retroviruses. Each of these eight tubes should also contain $4 \times 10^{6}$ irradiated HFFs.

$\Delta$ CRITICAL STEP Cells in fibroblast suspensions quickly settle down. Make sure to resuspend the contents of each tube thoroughly (by pipetting up and down) before counting cell numbers or transferring the required amounts of cell suspension to other tubes.

80 Centrifuge the $15-\mathrm{ml}$ conical tubes at $335 \mathrm{~g}$ for $5 \mathrm{~min}$ at $25^{\circ} \mathrm{C}$ and discard the supernatant. While cells are centrifuging, replace the lids on the gelatinized $100-\mathrm{mm}$ dishes and label them appropriately.

81| Resuspend the cells with $5 \mathrm{ml}$ of HDF medium and plate them into the gelatinized 100-mm dishes containing $5 \mathrm{ml}$ of HDF medium.

82 Place the dishes in the incubator and shake them three to four times forth-to-back and left-to-right to ensure a homogeneous distribution of the cells. Incubate the dishes at $37^{\circ} \mathrm{C}, 5 \% \mathrm{CO}_{2}$ for $24 \mathrm{~h}$.

83 Day 5: Aspirate the medium from the plates and add $10 \mathrm{ml}$ of HUES medium. Incubate the dishes at $37{ }^{\circ} \mathrm{C}, 5 \% \mathrm{CO}_{2}$. $\triangle$ CRITICAL STEP Do not put any HUES medium that has been pre-warmed back to $4^{\circ} \mathrm{C}$. To avoid this, make it a habit of calculating the amount of HUES medium that will be needed and only pre-warming that amount.

84| Days 6-14. Change HUES media every other day.

85| Days 15-60. Change HUES media daily until iPSC-like colonies appear.

86 At every $10 \mathrm{~d}$, or when the feeder layer of irradiated HFFs becomes too sparse (Fig. 3a,b), add $1 \times 10^{6}$ of fresh irradiated HFFs processed as in Step 77.

$\triangle$ CRITICAL STEP Reprogramming dishes are maintained for long periods of time (up to 2 months) and, thus, require many changes of medium. With time, the feeder layers may become quite thick and have a tendency to detach from the dish. To minimize this risk, observe extreme caution when changing the media: do not change the media to more than ten dishes at a time, do not aspirate the medium completely (leave some $\sim 2 \mathrm{ml}$ on the dish) and add the fresh medium very slowly $\left(\sim 1 \mathrm{ml} \mathrm{s}^{-1}\right)$ toward the side of the dish, rather than on top of the cells.

87| Beginning at day 13-15, hundreds of granulated colonies (Fig. 3c,d) will start appearing in the dishes infected with OSKM. Take no action, as they will eventually degenerate and disappear from the cultures. In OSK dishes, granulated colonies typically do not form, or they do so at much lower numbers (up to 15-20) beginning at around day 20. 
Figure 3 | Reprogramming genetically corrected fibroblasts. (a,b) Feeder layers of irradiated HFFs at an appropriate density to support reprogramming (a) or becoming too sparse $12 \mathrm{~d}$ after seeding (b). (c,d) Granulated colonies representing incomplete reprogramming events appear 2 weeks after transducing fibroblasts with OSKM retroviruses or after 3 weeks of OSK transduction. (c) A granulated colony of an OSK reprogramming experiment at day 25 illustrating the typical morphology. (d) Note the rough edges of the colony, not clearly defined from the fibroblasts of the feeder layer, at higher magnification. (e,f) Colonies of iPSC morphology appear 3-4 weeks after OSKM transduction or after 4-8 weeks of OSK transduction. (e) Small colony of iPSC-like morphology after $36 \mathrm{~d}$ of fibroblasts reprogramming with OSK. (f) Note the flat, epithelial morphology, the tightly packed cells and the sharp edges of the colony, more evident at higher magnification. $(\mathbf{g}, \mathbf{h})$ Colonies of iPSCs appearing in reprogramming plates grow very robustly and can become quite large. Shown are two examples of colonies measuring $>2 \mathrm{~mm}$ in diameter, with typical arrowhead-shaped growth fronts and undifferentiated morphology, ready to be picked. Scale bars $=100 \mu \mathrm{m}$ $(\mathbf{a}, \mathbf{b}), 250 \mu \mathrm{m}(\mathbf{c}, \mathbf{e}, \mathbf{g}, \mathbf{h})$ and $25 \mu \mathrm{m}(\mathbf{d}, \mathbf{f})$.

88| Colonies of iPSC morphology (Fig. 3e,f) will appear in dishes of genetically corrected fibroblasts transduced with OSKM at around days 21-30. Currently, we use these dishes just as a positive control of the procedure. Hence, we do not pick OSKM colonies for establishing iPSC lines. However, if desired, they can be picked as explained in Steps 91-97.
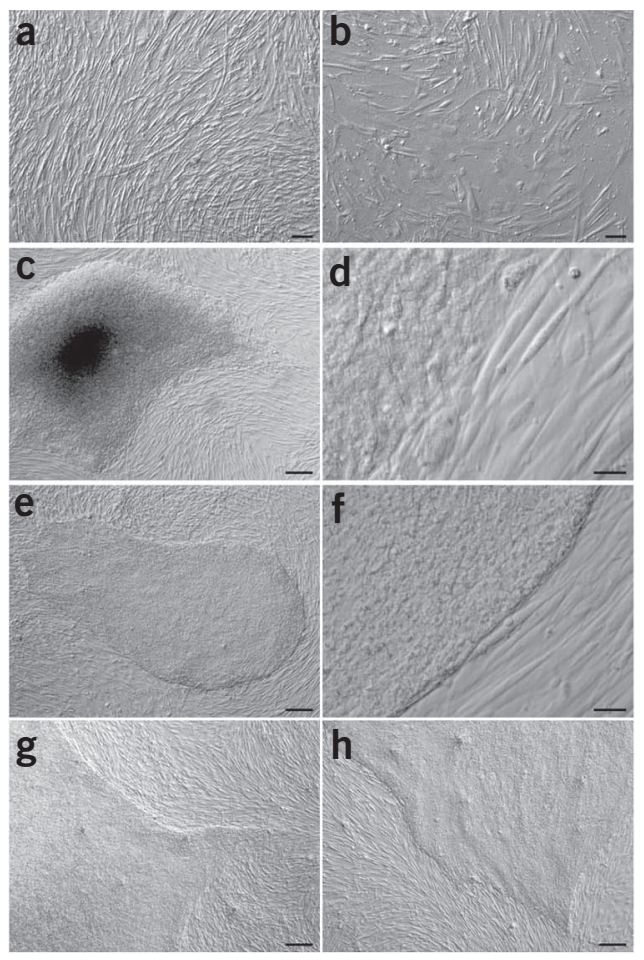

89| Colonies of iPSC morphology (Fig. 3e,f) will appear in dishes of genetically corrected fibroblasts transduced with OSK at around days 30-60. If properly maintained, these colonies will grow for up to 2 weeks ( $>5 \mathrm{~mm}$ in diameter) in the $100-\mathrm{mm}$ dishes before showing overt signs of differentiation (Fig. $\mathbf{3 g}, \mathbf{h}$ ). The best time to pick the colonies for establishing iPSC lines is when they are $\sim 1-2 \mathrm{~mm}$ in diameter. When several colonies in a dish have reached that size, go to Step 91.

90| In the case of FA fibroblasts, no iPSC-like colonies are obtained in the dishes of unmodified fibroblasts, but this may not be the case for other diseases. No iPSC-like colonies should appear at any time in the dishes of fibroblasts not infected with retroviruses (negative controls). Dishes in which no iPSC-like colonies appear after 2 months can be discarded.

\section{? TROUBLESHOOTING}

\section{Picking iPSC-like colonies TIMING $9 \mathrm{~d}$}

91| Day 1: Identify colonies of iPSC-like morphology (Fig. 3e-h) that grow robustly and circle them using a permanent ink, fine-point marking pen on the bottom of the dish under the inverted microscope with $5 \times$ objective.

92| Prepare the required number of six-well plates with irradiated HFF feeder layers, calculating one well per colony to be picked. For this, add $1 \mathrm{ml}$ of $0.1 \%$ gelatin to each well (ensuring that the gelatin solution completely covers the bottom of the dish) and incubate the plates at $37^{\circ} \mathrm{C}$ for 3-4 h. Aspirate the gelatin solution and leave the plates open to dry up completely. Plate irradiated HFFs $\left(6.67 \times 10^{5}\right.$ cells per well or $4 \times 10^{6}$ cells per plate) as in Step 77 . Incubate the plates overnight at $37^{\circ} \mathrm{C}, 5 \% \mathrm{CO}_{2}$.

93| Day 2: Replace the media of the reprogramming dish(es) and six-well feeder plates with fresh HUES medium 1-2 $\mathrm{h}$ before picking colonies.

94| Working on the stereomicroscope placed inside a tissue culture hood, use a 'stripper' micropipette and $150 \mu \mathrm{m}$ tips to carefully lift and aspirate the colony. This will break up the colony in dozens of 25-100-cell fragments. Transfer the colony fragments into a well with feeders (passage 1).

$\triangle$ CRITICAL STEP If operated correctly, the same tip can be used to pick many independent colonies with no risk of crosscontamination, by washing the tip two to three times sequentially in three wells of a six-well plate each containing $2 \mathrm{ml}$ of HUES medium. Alternatively, especially if not familiarized with the use of the 'stripper' micropipette, replace the tip after picking each colony. 
95| Once a six-well plate is completed, transfer it to the incubator and shake it 3-4 times forth-to-back and left-to-right to ensure a homogeneous distribution of the fragments. Leave the plates undisturbed at $37{ }^{\circ} \mathrm{C}, 5 \% \mathrm{CO}_{2}$ for $48 \mathrm{~h}$.

96| Day 4: Aspirate the medium of the plates and add $2 \mathrm{ml}$ of HUES to each well. Many colony fragments should be attached to the feeder cells.

97| Days 5-9: Change the medium daily. Attached colony fragments will form fully grown iPSC-like colonies, ready to be passaged, by days $8-9$.

? TROUBLESHOOTING

\section{Optimized expansion of iPSC lines for rapid characterization $\bigcirc$ TIMING 6 weeks}

98| Pick the colonies of a passage-1 iPSC culture and plate them onto one well of a six-well plate with irradiated HFFs (1:1 split), as described in Steps 94-95 (passage 2). Select only the portions of the colonies with the best, undifferentiated morphology. Keep the wells of the original (passage 1) cultures, as colonies will quickly re-grow and can be picked again in 3-4 $\mathrm{d}$ and frozen into one vial. Discard the cultures after having been picked twice. Do this after every passage until enough backup vials (approximately five vials per line) have been frozen.

99| After 6-7 d, the colonies of passage-2 cultures will be ready for passage. Split them again mechanically at a 1:2 ratio onto two wells of a six-well plate with feeders (passage 3 ).

100 After 6-7 d, pick the colonies in one of the wells and freeze them into two vials. Pick the colonies of the other well and split in the ratio of 1:2 onto one well of a six-well plate with feeders and one well coated with Mg (see Box 2 for preparing Mg-coated plates). These subcultures represent passage 4 and passage $4 / \mathrm{Mg}+1$, respectively.

$\triangle$ CRITICAL STEP Feeder-free cultures should be maintained with HUES medium conditioned by mouse embryo fibroblasts (MEFs). Preparation, expansion and irradiation of MEFs are described in reference 24.

101| When the colonies of passage-4 cultures are ready to be passaged, pick them and split them in the ratio 1:2 onto one well of a six-well plate with feeders (passage 5). Use the remaining fragments of colonies (half of the well) to form embryoid bodies for assessing differentiation potential in vitro (see ref. 25).

102 When the colonies of passage- $4 / \mathrm{Mg}+1$ cultures are ready to be passaged, aspirate the medium, wash the well with $2 \mathrm{ml}$ of PBS, trypsinize with $0.5 \mathrm{ml}$ of pre-warmed $0.05 \%$ trypsin/EDTA for 2 min at room temperature and collect the dissociated cells with $3 \mathrm{~mL}$ of MEF-conditioned HUES medium into a 15-ml conical tube. Pipette the cell suspension up and down 10 times to generate a single cell (sc) suspension and plate it onto a 100-mm Mg-coated dish containing $7 \mathrm{ml}$ of MEF-conditioned HUES medium (passage $5 / \mathrm{Mg}+2 / \mathrm{sc}+1$ ).

103 After 6-7 d, pick the colonies in passage- 5 cultures and split them in the ratio of 1:2 onto one well of a six-well plate with feeders (passage 6). Plate the remaining fragments of colonies (half of the well) onto three slide flasks with feeders for immunofluorescence analyses of pluripotency-associated transcription factors (OCT4, SOX2, NANOG) and surface markers (SSEA-3, SSEA-4, TRA1-60, TRA1-81), as described in reference 13. Immunostaining with OCT4 and SOX2 may reflect exogenous expression from the retroviral transgenes, which can be easily ruled out by co-staining with anti-FLAG antibodies ${ }^{9}$.

104 When ready for passaging, trypsinize passage-5/Mg $+2 / \mathrm{sc}+1$ cultures as in Step 102 and split at a 1:4 ratio onto $4 \times 100-\mathrm{mm} \mathrm{Mg-coated} \mathrm{dishes} \mathrm{(passage} 6 / \mathrm{Mg}+3 / \mathrm{sc}+2$ ).

105 Maintain cultures of colonies on feeders in six-well plates by mechanical passaging of passage- 6 cultures, at splitting ratios of 1:2-1:3, using one of the wells for maintaining the line and freezing the colonies of the other well(s) in two vials per well.

106 After 5-6 d, the four 100-mm dishes of passage- $6 / \mathrm{Mg}+3 / \mathrm{sc}+2$ cultures will be ready for processing. Use one of the dishes for freezing five backup vials.

107| Use 1 dish of passage-6/Mg $+3 / s c+2$ cells for karyotyping (see ref. 25).

108| Trypsinize the colonies of the remaining two dishes as in Step 102 and combine the cell suspensions, count the cell number and use $2 \times 10^{6}$ cells to form teratomas in two immunodeficient mice, as described in reference 13 . 
109 Divide the remaining cell suspension into two 15 - $\mathrm{ml}$ conical tubes, centrifuge at $335 \mathrm{~g}$ for $5 \mathrm{~min}$ at $25^{\circ} \mathrm{C}$, discard the supernatants and collect the cells with $1 \mathrm{ml}$ of PBS into screw-cap microcentrifuge tubes. Centrifuge the tubes at $845 \mathrm{~g}(3,000$ r.p.m. in an Eppendorf 5424 centrifuge with 24-tube rotor) for $5 \mathrm{~min}$ at room temperature. Discard the supernatants and store the pellets at $-80^{\circ} \mathrm{C}$ for later use. One of the pellets can be used for extracting genomic DNA for DNA fingerprinting (ref. 25) and analyzing viral integrations by PCR, quantitative PCR and/or Southern blot (ref. 9). The other pellet can be used to purify RNA to assess the silencing of retroviral transgenes (ref. 13), the expression of the gene-therapy transgene (ref. 9) and the endogenous expression of pluripotency-associated transcription factors (ref. 13), by quantitative reverse transcriptase-PCR.

$\triangle$ CRITICAL STEP Passaging of iPSC lines as single cells in feeder-free cultures should not be carried out for more than five sequential passages, as cells acquiring karyotypic abnormalities that confer growth advantage may rapidly take over the culture. We only do massive expansion of iPSC lines in this way to quickly generate enough sample material for downstream analyses. For long-term maintenance of iPSC lines, we always maintain a culture passaged by mechanical picking of colonies.

\section{TIMING}

Steps 1-22, Establishment of patients' primary cell cultures: 6 weeks

Steps 23-38, Production of gene correction lentiviruses: $7 \mathrm{~d}$

Steps 39-45, Titration of gene correction lentiviral stocks: $9 \mathrm{~d}$

Steps 46-55, Gene therapy of patients' somatic cells: $7 \mathrm{~d}$

Steps 56-69, Production of reprogramming retroviruses: $7 \mathrm{~d}$

Steps 70-90, Reprogramming genetically corrected somatic cells: 4-8 weeks

Steps 91-97, Picking iPSC-like colonies: $9 \mathrm{~d}$

Steps 98-109, 0ptimized expansion of iPSC lines for rapid characterization: 6 weeks

\section{? TROUBLESHOOTING}

Troubleshooting advice can be found in Table 1.

TABLE 1 | Troubleshooting table.

\begin{tabular}{lll}
\hline Step & Problem & Possible reason and solution \\
\hline 9 & $\begin{array}{l}\text { Biopsy pieces have been dried } \\
\text { up, no culture medium left }\end{array}$ & Check incubator. The water reservoir may be empty
\end{tabular}

11 Presence of contaminant keratinocytes in fibroblast dishes Low lentiviral titer Low transduction efficiency No iPSC-like colonies appear after passage 1
After 1 week of culture, outgrowths of epidermal keratinocytes may appear from some biopsy pieces. This is more evident when using cover slips. Take no action; keratinocytes will not thrive in HDF medium and will die away by the time fibroblasts become ready for passaging

Low titers of LV preparations can be obtained when using highly passaged 293T cells and/or when the DNA for transfection is not of good quality. If this is the case, try thawing a vial of 293T cells under passage 18 and/or using endotoxin-free maxiprep kits for plasmid DNA purification

Transduction efficiency varies considerably (30-90\%) among different HDF cultures. If no fluorescence is observed at all, the microscope may not be sensitive enough (GFP expression is low in these cells, as it is placed after an IRES element and driven by a weak SFFV promoter). Try with a more sensitive microscope or flow cytometry. If the titer of the LV stock was adequate $\left(>5 \times 10^{7} \mathrm{TU} \mathrm{mL}^{-1}\right)$ and the percentage of GFP-positive cells is below $30 \%$, the LV stock may have deteriorated or the fibroblasts may be particularly refractory to LV transduction. In the first case, try with a new vial of LV stock and avoid freeze-thaw cycles. In the second case, try infecting the fibroblasts twice, $24 \mathrm{~h}$ apart

In our experience with $>30$ independent samples so far, generation of iPSC colonies from passage- 4 fibroblasts (or keratinocytes), processed as described here, is 100\% with 0SKM. If iPSC colonies do not appear in OSKM (positive control) plates, most probably the reprogramming retroviral supernatants were not of high enough titer. If iPSC colonies do appear in OSKM dishes, but not in those transduced with OSK, it is most likely that the specific fibroblasts used were refractory to reprogramming. We have found three such samples so far $(\sim 10 \%)$, not appearing to be related to the donors' age. Repeat the procedure with fibroblasts (or keratinocytes) isolated from a different donor. Alternatively, a $2 \mathrm{i}$-selection step can be included in Steps 84-85 of the protocol, supplementing the media with $1 \mu \mathrm{M}$ PD0325901 and $1 \mu \mathrm{M}$ CT99021 from day 12 until day 19

The colony picked was not an iPSC colony. Most likely, an unusually compact granular colony was mistaken for an iPSC-like colony. To avoid this, pay special attention to the edges of the colonies, which should be sharp and defined, when selecting those to be picked 
Figure 4 | Genetically corrected FA-iPSCs are pluripotent. (a-d) iPSCs generated by retroviral transduction with 0CT4, SOX2 and KLF4 of genetically corrected FA somatic cells (cell line cFA404-KiPS3F1) show expression of the transcription factors (a) OCT4, (b) SOX2 and (c) NANOG and the surface markers (a) SSEA3, (b) SSEA4 and (c) TRA1-60 and (d) strong AP staining. (e-g) In vitro differentiation of cFA404-KiPS3F1 cells toward endoderm (e, $\alpha$-fetoprotein; FoxA2) and ectoderm (f, TuJ1) derivatives. (g) Hematopoietic progenitor cells (mesoderm derivatives) at day 10 of differentiation. Scale bars $=100 \mu \mathrm{m}$. Images are modified from a figure originally published in reference 9 .

\section{ANTICIPATED RESULTS}

At the end of the protocol, one should have generated a variety of iPSC lines from genetically corrected fibroblasts or keratinocytes, which will be thoroughly characterized as bona fide human pluripotent cells (Fig. 4). Assessing self-renewal ability will require long-term (>20 passages) culture propagation, which we carry out by mechanical passaging on feeders. In the case of FA, iPSC lines generated from genetically corrected fibroblasts or keratinocytes maintain expression levels of the lentiviral FANCA transgene above the threshold necessary for phenotypic correction, whereas the reprogramming retroviral transgenes are nearly completely silenced ${ }^{9}$. Although some inactivation of the lentiviral promoter can take place in iPSCs, in the case of FA, a proliferation advantage of iPSCs expressing above-threshold levels of the FANCA transgene will occur. For other conditions, selection of iPSC clones maintaining adequate expression levels of the correcting genes would be required. Alternatively, in conditions in which gene therapy is not required for the generation of iPSC lines, transduction with the correcting vector could be conducted once these cells are established.
ACKNOWLEDGMENTS We are indebted to FA patients and their families for their kind cooperation. We are grateful to all the members of the laboratory for advice and discussion and to Begoña Arán, Meritxell Carrió, Yolanda Muñoz and M. Luz partially supported by the Ministerio de Educación y Ciencia grants BFU2009-13277, BFU2006-12247, SAF2009-07164, PLE2009-0144, PLE2009-0100 and Genoma España (FANCOGENE), European Commission 'Marie-Curie Reintegration Grant' MIRG-CT-2007-046523 and FP7-PERSIST Rej: 222878, the Fondo de Investigaciones Sanitarias (RETIC-RD06/0010/0016, RD06/0010/0015 and PI061897), Marató de TV3 (063430), the G. Harold and Leila Y. Mathers Charitable Foundation, Fundación Marcelino Botín and Fundación Cellex.

AUTHOR CONTRIBUTIONS A.R. designed the overall protocol, generated and characterized the FA-iPS cells and wrote the manuscript after obtaining the material from all authors; I.R.-P., Y.R.-P., A.S.-D. and A.C. designed the reprogramming protocol and characterized the FA-iPS cells; S.N., G.G. and J.B. designed the gene therapy correction protocol and prepared the gene therapy lentiviruses; and J.C.I.B. supervised the project.

Published online at http://www.natureprotocols.com/.

Reprints and permissions information is available online at http://npg.nature.com/ reprintsandpermissions/.

1. Takahashi, K. \& Yamanaka, S. Induction of pluripotent stem cells from mouse embryonic and adult fibroblast cultures by defined factors. Cell 126, 663-676 (2006).

2. Takahashi, K. et al. Induction of pluripotent stem cells from adult human fibroblasts by defined factors. Cell 131, 861-872 (2007).

3. $\mathrm{Yu}, \mathrm{J}$. et al. Induced pluripotent stem cell lines derived from human somatic cells. Science 318, 1917-1920 (2007).

4. Park, I.H. et al. Reprogramming of human somatic cells to pluripotency with defined factors. Nature 451, 141-146 (2008). Lozano for their expert assistance with cell culture techniques. This work was

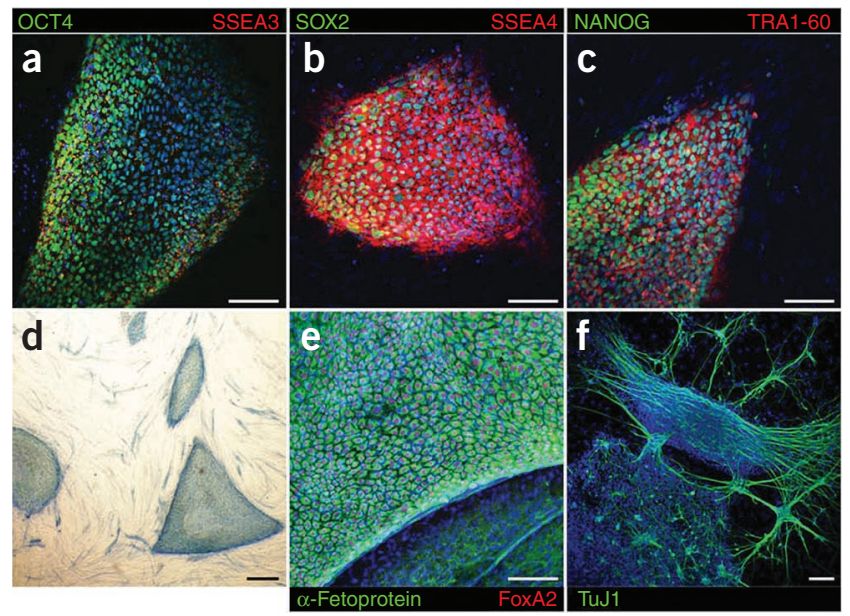

g

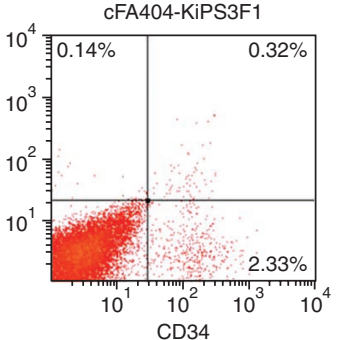

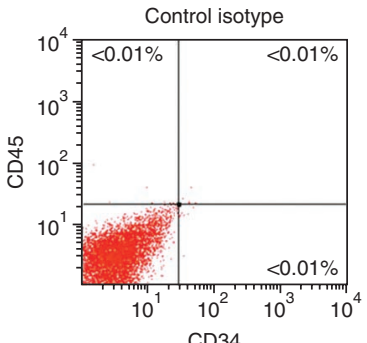

from dermal fibroblasts. Proc. Nat. Acad. Sci. USA 105, 2883-2888 (2008)

6. Park, I.H. et al. Disease-specific induced pluripotent stem cells. Cell 134, 877-886 (2008).

7. Dimos, J.T. et al. Induced pluripotent stem cells generated from patients with ALS can be differentiated into motor neurons. Science 321, 1218-1221 (2008).

8. Ebert, A.D. et al. Induced pluripotent stem cells from a spinal muscular atrophy patient. Nature 457, 277-280 (2009).

9. Raya, A. et al. Disease-corrected haematopoietic progenitors from Fanconi anaemia induced pluripotent stem cells. Nature 460, 53-59 (2009).

10. Hong, H. et al. Suppression of induced pluripotent stem cell generation by the p53-p21 pathway. Nature 460, 1132-1135 (2009).

11. Kawamura, T. et al. Linking the $\mathrm{p} 53$ tumour suppressor pathway to somatic cell reprogramming. Nature 460, 1140-1144 (2009).

12. Marion, R.M. et al. A p53-mediated DNA damage response limits reprogramming to ensure iPS cell genomic integrity. Nature 460, 1149-1153 (2009).

13. Aasen, T. et al. Efficient and rapid generation of induced pluripotent stem cells from human keratinocytes. Nat. Biotechnol. 26, 1276-1284 (2008).

14. Takahashi, K., Okita, K., Nakagawa, M. \& Yamanaka, S. Induction of pluripotent stem cells from fibroblast cultures. Nat. Protoc. 2, 3081-3089 (2007).

15. Park, I.H., Lerou, P.H., Zhao, R., Huo, H. \& Daley, G.Q. Generation of human-induced pluripotent stem cells. Nat. Protoc. 3, 1180-1186 (2008).

16. Ying, Q.L. et al. The ground state of embryonic stem cell self-renewal. Nature 453, 519-523 (2008).

17. Stadtfeld, M., Nagaya, M., Utikal, J., Weir, G. \& Hochedlinger, K. Induced pluripotent stem cells generated without viral integration. Science $\mathbf{3 2 2}$, 945-949 (2008).

18. Okita, K., Nakagawa, M., Hyenjong, H., Ichisaka, T. \& Yamanaka, S. Generation of mouse induced pluripotent stem cells without viral vectors. Science 322, 949-953 (2008). 
PROTOCOL

19. Kim, D. et al. Generation of human induced pluripotent stem cells by direct delivery of reprogramming proteins. Cell Stem Cell 4, 472-476 (2009).

20. Zou, J. et al. Gene targeting of a disease-related gene in human induced pluripotent stem and embryonic stem cells. Cell Stem Cell 5, 97-110 (2009).

21. Baum, C. et al. The potent enhancer activity of the polycythemic strain of spleen focus-forming virus in hematopoietic cells is governed by a binding site for Sp1 in the upstream control region and by a unique enhancer core motif, creating an exclusive target for PEBP/CBF. J. Virol. 71, 6323-6331 (1997).

22. Aasen, T. \& Belmonte, J.C. Isolation and cultivation of human keratinocytes from skin or plucked hair for the generation of induced pluripotent stem cells. Nat. Protoc. 5, 371-382 (2010).

23. Jacome, A. et al. Lentiviral-mediated genetic correction of hematopoietic and mesenchymal progenitor cells from Fanconi anemia patients. Mol. Ther. 17, 1083-1092 (2009).

24. Lerou, P.H. et al. Derivation and maintenance of human embryonic stem cells from poor-quality in vitro fertilization embryos. Nat. Protoc. 3, 923-933 (2008).

25. Raya, A. et al. Generation of cardiomyocytes from new human embryonic stem cell lines derived from poor-quality blastocysts. Cold Spring Harb. Symp. Quant. Biol. 73, 127-135 (2008). 